\title{
The role of tissue factor and P-selectin in the procoagulant response that occurs in the first month after on-pump and off-pump coronary artery bypass grafting
}

\author{
Alessandro Parolari, MD, $\mathrm{PhD}^{\text {a }}$ Luciana Mussoni, $\mathrm{PhD},{ }^{\mathrm{b}}$ Marta Frigerio, $\mathrm{PhD},{ }^{\text {a }}$ Moreno Naliato, $\mathrm{MD},{ }^{\text {a }}$ \\ Francesco Alamanni, MD, ${ }^{a}$ Gian Luca Polvani, MD, ${ }^{a}$ Marco Agrifoglio, MD, PhD, ${ }^{a}$ Fabrizio Veglia, PhD, \\ Elena Tremoli, PhD, ${ }^{\mathrm{a}, \mathrm{b}}$ Paolo Biglioli, MD, ${ }^{\mathrm{a}}$ and Marina Camera, BiolSci, PhD ${ }^{\mathrm{a}, \mathrm{b}}$
}

Supplemental material is available online.
From the Department of Cardiac Surgery ${ }^{\mathrm{a}}$ and the Biostatistics Unit ${ }^{\mathrm{c}}$, Centro Cardiologico Monzino IRCCS, Milan, Italy, and the Department of Pharmacological Sciences, University of Milan, Milan, Italy.

Received for publication April 12, 2005; revisions received July 26, 2005; accepted for publication July 29, 2005

Address for reprints: Alessandro Parolari, MD, PhD, Department of Cardiac Surgery, University of Milan, Centro Cardiologico, Fondazione Monzino IRCCS, Via Parea, 4, 20138, Milano, Italy (E-mail: alessandro. parolari@ cardiologicomonzino.it).

J Thorac Cardiovasc Surg 2005;130:1561-6 $0022-5223 / \$ 30.00$

Copyright (C) 2005 by The American Association for Thoracic Surgery

doi:10.1016/j.jtcvs.2005.07.049
Background: It has been previously shown that a persistent (up to 1 month) prothrombotic status occurs after coronary bypass surgery performed both on pump and off pump. To assess the pathways involved in the occurrence of postoperative prothrombotic state, in this study we evaluated plasma, monocyte-bound, and platelet-bound tissue factor expression, as well as platelet and soluble P-selectin expression, up to 1 month after off-pump and on-pump coronary artery bypass grafting.

Methods: Thirty patient candidates for coronary surgery were randomized to undergo off-pump coronary artery bypass grafting $(n=15)$ or on-pump coronary artery bypass grafting $(n=15)$. Blood samples were collected before the intervention, after protamine administration, and 4, 8, and 30 days after surgical intervention.

Results: Plasma tissue factor levels were significantly higher than baseline both in the on-pump coronary artery bypass grafting group (from protamine administration up to 4 postoperative days) and in the off-pump coronary artery bypass grafting group (at 4 postoperative days), with no differences between groups. Basal and lipopolysaccharide-stimulated monocyte tissue factor expression, as well as basal and adenosine diphosphate-stimulated platelet tissue factor expression, did not show significant variations over time and were similar in the on-pump and off-pump coronary artery bypass grafting groups throughout the course of the study. Platelet expression of P-selectin, both basal and after adenosine diphosphate stimulation, did not significantly change over time and was not different in the on-pump and off-pump coronary artery bypass grafting groups. Soluble P-selectin levels in plasma were significantly higher in patients receiving on-pump coronary artery bypass grafting only at the time point after protamine administration, whereas this variable behaved similarly in the on-pump and off-pump coronary artery bypass grafting groups for the whole postoperative period.

Conclusions: The postoperative tissue factor and P-selectin expression did not differ between the on-pump and off-pump coronary artery bypass grafting groups. The distinct increase of plasma tissue factor occurring after both surgical procedures might represent a mechanism that might explain, in part, the early postoperative prothrombotic state occurring after on-pump and off-pump coronary artery bypass grafting.

I has been previously shown that a sensible activation of the hemostaticthrombotic and inflammatory systems occurs during the intervention and persists for several weeks after coronary artery bypass surgery. ${ }^{1-4}$ This activation is more marked in patients undergoing on-pump coronary artery bypass grafting $(\mathrm{CABG})$, which lasts for the limited time span during the operation and in the very 


$$
\begin{aligned}
& \text { Abbreviations and Acronyms } \\
& \begin{aligned}
\text { ADP } & =\text { adenosine diphosphate } \\
\text { ANOVA } & =\text { analysis of variance } \\
\text { CABG } & =\text { on-pump coronary artery bypass grafting } \\
\text { FITC } & =\text { fluorescein isothiocyanate } \\
\text { GLM } & =\text { general linear model } \\
\text { mAb } & =\text { monoclonal antibody } \\
\text { MFI } & =\text { mean fluorescence intensity } \\
\text { OPCAB } & =\text { off-pump coronary artery bypass grafting } \\
\text { PE } & =\text { phycoerythrin } \\
\text { TF } & =\text { tissue factor } \\
\text { WB } & =\text { whole blood }
\end{aligned}
\end{aligned}
$$

\section{Anesthesia}

Patient management during and after the operation was the same in both groups of patients. All patients continued their cardiac medications until the operation.

Patients received thiopentone, 3 to $5 \mathrm{mg} / \mathrm{kg}$, and fentanyl, $1 \mu \mathrm{g} / \mathrm{kg}$, as induction and were maintained with sufentanil boluses of up to 4 to $5 \mu \mathrm{g} / \mathrm{kg}$ associated with propofol (Diprivan, AstraZeneca) continuous infusion at $3 \mathrm{mg} \cdot \mathrm{kg}^{-1} \cdot \mathrm{h}^{-1}$.

After orotracheal intubation, patients were ventilated with oxygen and air (fraction of inspired oxygen, 50\%), maintaining $\mathrm{PaCO}_{2}$ at between 35 and $38 \mathrm{~mm} \mathrm{Hg}$. Rectal and cervical esophageal probes were used for temperature monitoring, and acid-base equilibrium was maintained by using the alpha-stat method.

After internal thoracic artery takedown, systemic heparinization (300 IU/kg bovine lung heparin) was given in both groups, and anticoagulation was assessed with celite ACT, with a trigger level for additional heparin set at 440 seconds every 30 minutes during cardiopulmonary bypass ( $\mathrm{CPB}$; in the $\mathrm{CABG}$ group) or during coronary anastomosis confection (in the OPCAB group).

On completion of distal and proximal coronary anastomoses, heparin was antagonized with protamine sulfate at a 1:1 ratio $(3 \mathrm{mg} / \mathrm{kg}$ ) in both groups. The protamine dose was based on total heparin used during the operation.

\section{CABG Surgery}

A nonpulsatile roller pump, hollow-fiber oxygenator with integrated heat exchanger, arterial filter, open cardiotomy reservoir, and polyvinyl tubing system were used in all cases. Each operation was performed with tepid hypothermia $\left(32^{\circ} \mathrm{C}-34^{\circ} \mathrm{C}\right)$ and hemodilution. Blood flow during CPB was kept at $2.4 \mathrm{~L} \cdot \mathrm{min}^{-1} \cdot \mathrm{m}^{-2}$, and hematocrit was kept at $18 \%$ to $25 \%$. Myocardial protection was achieved through the administration of cold $\left(4^{\circ} \mathrm{C}\right)$ multidose blood cardioplegia infused through the aortic root and the coronary sinus.

\section{OPCAB Surgery}

All OPCAB surgeries were performed through a midline sternotomy; mechanical stability of the coronary arteriotomy area was achieved with a suction stabilizer, and a soft plastic coronary flow shunt was always introduced into the coronary arteriotomy to maintain some degree of distal flow, to reduce myocardial ischemia, and to improve visualization of the anastomosis area. Coronary artery exposure was achieved with stay sutures applied on the left lateral side of the pericardium or with deep pericardial stay sutures placed above the entry to the left lower pulmonary vein and laterally to the entry of the inferior vena cava (Lima stitch).

\section{Follow-up}

All the patients were hospitalized until the 8th postoperative day. Then all patients underwent a follow-up visit (physical examination, electrocardiograph, and blood collection) at the 30th postoperative day.

\section{Blood Sampling}

Blood collection was performed from the antecubital vein through a 19-gauge needle without venous stasis. After discarding the first $4 \mathrm{~mL}$, blood was drawn into citrate-containing (1:10 vol sodium citrate $0.129 \mathrm{~mol} / \mathrm{L}$ ) Vacutainer tubes (Becton Dickinson) at base- 
line (the day before the operation), 5 minutes after protamine administration, at stable hemodynamic conditions, and at 4, 8, and 30 days after surgical intervention. Plasma was prepared by means of centrifugation at $1500 \mathrm{~g}$ for 20 minutes at $4^{\circ} \mathrm{C}$ within 30 minutes from venipuncture, divided into aliquots, and frozen at $-80^{\circ} \mathrm{C}$ until assayed.

For laboratory methods please see the Electronic Appendix.

\section{Statistical Analysis}

The study was powered to detect, with a power of $80 \%$, an $\alpha$ error of .05 , a percentage change from baseline equal to 1 standard deviation in any time point. Continuous variables are presented as means \pm 1 standard error of the mean, and categoric variables are presented as percentages. Group differences in clinical variables between the $\mathrm{CABG}$ and $\mathrm{OPCAB}$ groups were assessed with analysis of variance (ANOVA) and $\chi^{2}$ or Fisher exact tests when indicated.

General linear model (GLM) ANOVA models were used for statistical analysis of time, group (CABG vs OPCAB), and interaction (time * group) effects (main effects) in hematologic variables assessed as percentage variations from baseline values. When time, group, or interaction effects were significant $(P \leq$ $.05)$, repeated-measures ANOVA with the Bonferroni correction was used to determine significant $(P \leq .05)$ point-by-point differences.

\section{Results}

Absolute values of tissue factor and p-selection are reported in the electronic pages (Table E2).

\section{Tissue Factor}

Plasma TF. Baseline plasma TF levels were similar in the CABG and OPCAB groups $(157 \pm 5.5$ and $145 \pm 6.2$ $\mathrm{pg} / \mathrm{mL}$, respectively). GLM ANOVA showed a significant effect of time $(P=.045)$ but not of treatment $(P=.57)$; point-by-point analysis documented significant increases with respect to the baseline occurring both in the $\mathrm{CABG}$ group (after protamine: $+72 \% \pm 20 \%, P=.02 ; 4$ days postoperatively: $+83 \% \pm 26 \%, P=.03$ ) and the OPCAB group (4 days postoperatively: $+98 \% \pm 33 \%, P=.05$; Figure 1, A).

Monocyte TF expression. Basal and lipopolysaccharide-stimulated monocyte TF expression was similar in the CABG and OPCAB groups before the operation (basal: $0.95 \pm 0.043$ and $0.95 \pm 0.037$ mean fluorescence intensity [MFI], respectively; stimulated: $1.59 \pm 0.094$ and $1.46 \pm$ $0.115 \mathrm{MFI}$, respectively) and did not change in either group throughout the course of the study (Figure 1, $B$ and $C$ ).

Platelet TF expression. Unstimulated and stimulated platelet $\mathrm{TF}$ expression was similar in the CABG and OPCAB groups before the operation (unstimulated: $2.15 \pm$ 0.208 and $1.83 \pm 0.150 \mathrm{MFI}$, respectively; stimulated: $3.37 \pm 0.182$ and $3.15 \pm 0.230 \mathrm{MFI}$, respectively). The analysis of TF expression in unstimulated platelets showed a significant effect of time $(P=.018)$; point-by-point anal- ysis, however, did not show any significant difference with respect to baseline in both groups (Figure 1, D). Adenosine diphosphate (ADP)-induced platelet TF expression did not change throughout the study in either the CABG or OPCAB group (Figure 1, E).

\section{P-selectin}

Platelet P-selectin expression. Unstimulated and stimulated platelet $\mathrm{P}$-selectin expression was similar in the $\mathrm{CABG}$ and OPCAB groups before the operation (unstimulated: $0.94 \pm 0.019$ and $0.90 \pm 0.035 \mathrm{MFI}$, respectively; stimulated: $3.97 \pm 0.496$ and $2.67 \pm 0.416 \mathrm{MFI}$, respectively). Both unstimulated and stimulated P-selectin expression did not show significant variations over time or differences between patients assigned to the $\mathrm{CABG}$ and OPCAB groups (Figure 2, $A$ and $B$ ).

Soluble P-selectin. Soluble P-selectin levels were similar at baseline in the CABG and OPCAB groups $(101 \pm 3.7$ and $93 \pm 3.0 \mathrm{ng} / \mathrm{mL}$, respectively). GLM ANOVA showed a significant effect of time $(P<.001)$, treatment $(P<.036)$, and interaction $(P=.013)$ terms; point-by-point analysis showed no differences over time in the OPCAB group, whereas in the $\mathrm{CABG}$ group there was a significant increase with respect to baseline after protamine administration $(+41 \% \pm 10 \%, P=.05)$. At this time point, there was also a significant difference between the $\mathrm{CABG}$ and OPCAB groups $(+41 \% \pm 10 \%$ and $-23 \% \pm 10 \%$, respectively; $P<.001$ ), whereas no differences could be demonstrated in the postoperative period both with respect to baseline and between the CABG and OPCAB groups (Figure 2, C).

\section{Discussion}

Several studies have documented major changes in hemostatic variables occurring during and early after CABG performed with the use of CPB. Activation of the extrinsic coagulation pathway occurs during surgical intervention and is due to blood that first comes into contact with nonendothelial surfaces of the pump and especially of the surgical wound and then is directed to the pump; this is an important trigger for intraoperative coagulation activation because it is followed by early and sharp increases of thrombin generation markers. ${ }^{7,8}$ Likewise, sensible platelet activation has been documented to occur during and in the early phases after coronary surgery, being characterized by increased platelet expression of P-selectin and also increased levels of its soluble form. ${ }^{9}$

The above-mentioned evidence comes, however, from studies that were focused on the very early phase after surgical intervention, extending observation times for a maximum of 24 to 48 hours after $\mathrm{CABG}$. A protracted prothrombotic state occurring after CABG was recently demonstrated, ${ }^{1}$ even though the mechanisms underlying this state have not been investigated yet. Moreover, a sensible activation of hemo- 

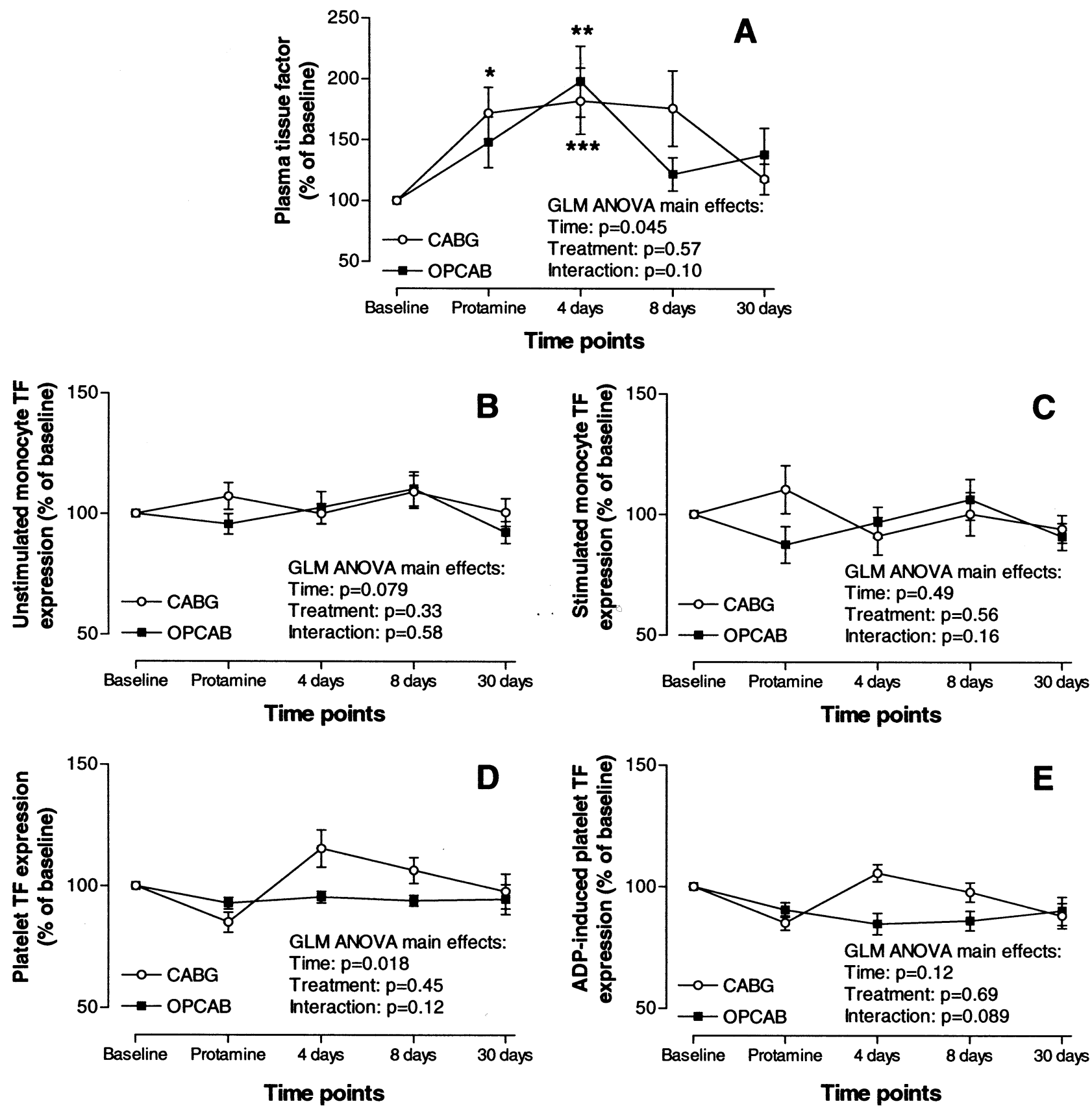

Figure 1. Tissue factor (TF). Plasma tissue factor (A), baseline monocyte tissue factor (B), lipopolysaccharidestimulated monocyte tissue factor (C), baseline platelet tissue factor (D), and adenosine diphosphate (ADP)stimulated platelet tissue factor (E) are shown at each time interval. Data are presented as means \pm 1 standard error of the mean. Open circles indicate patients assigned to on-pump coronary artery bypass grafting (CABG; $\mathbf{n}$ $=15$ ), and filled squares indicate patients assigned to off-pump coronary artery bypass grafting (OPCAB; $n=15)$. ${ }^{*} P=.02,{ }^{*} P=.05,{ }^{* *} P=.03$ versus baseline. GLM ANOVA, General linear model analysis of variance.

static pathways has been documented also after coronary surgery performed off pump; this activation is of relatively lower degree in off-pump coronary surgery during and in the very early hours thereafter, ${ }^{5,11}$ whereas at later times, the extent of this activation is similar between on-pump and off-pump procedures ${ }^{5}$; this led to the hypothesis that extra- 

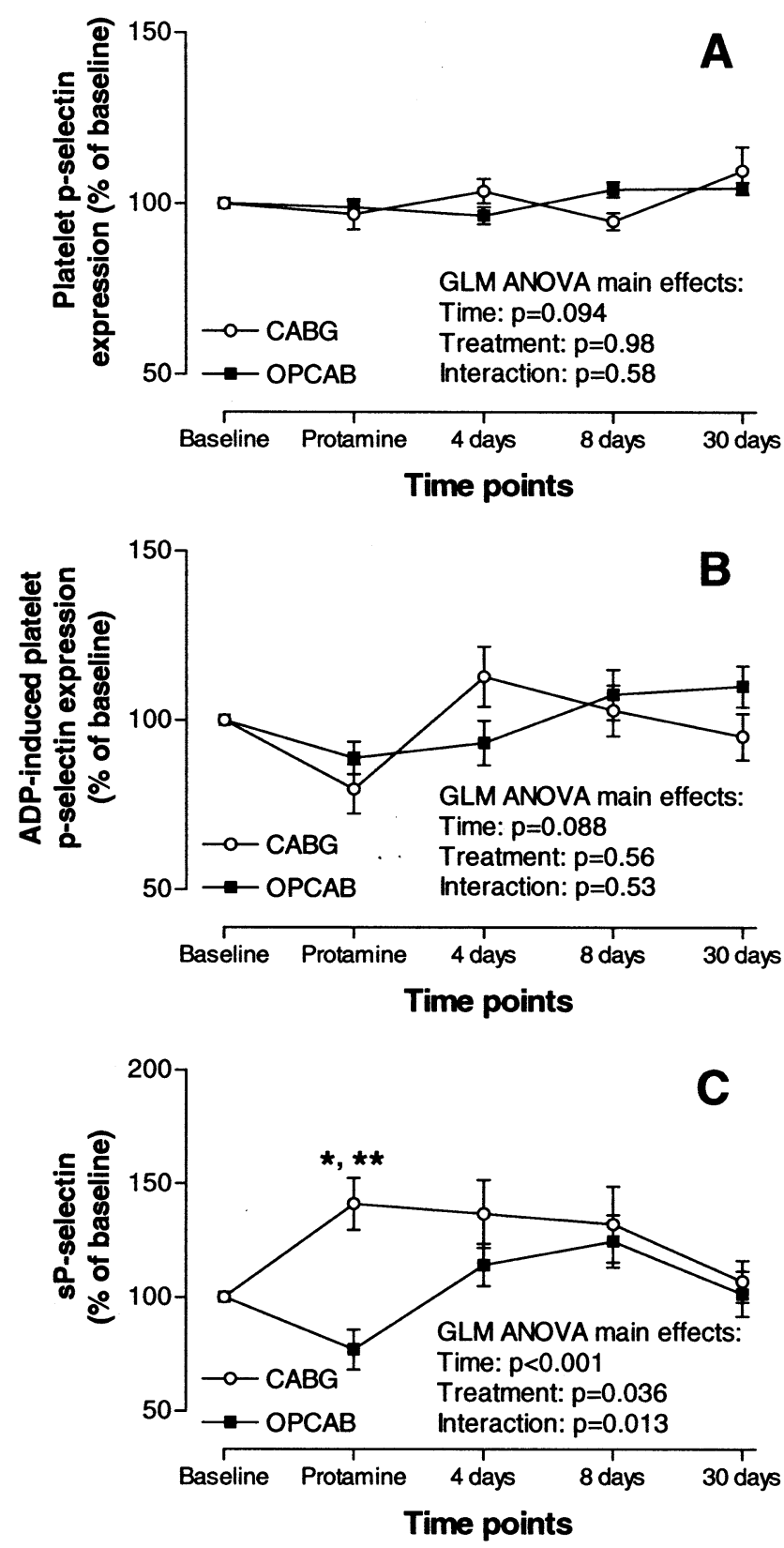

Figure 2. P-selectin. Baseline platelet P-selectin (A), adenosine diphosphate (ADP)-stimulated platelet P-selectin (B), and soluble P-selectin (C) expression are shown at each time interval. Data are presented as means \pm 1 standard error of the mean. Symbols are as in Figure 1. ${ }^{*} \boldsymbol{P}=.002$ vs baseline and ${ }^{*} \boldsymbol{P}<.001$, on-pump coronary artery bypass grafting (CABG) versus off-pump coronary artery bypass grafting (OPCAB). GLM ANOVA, General linear model analysis of variance.

corporeal circulation is the cause of the perturbations occurring early after surgical intervention, whereas surgical trauma is likely to be responsible for the later ones. ${ }^{12}$
Our study shows that the delayed activation of the coagulation that occurs after coronary bypass surgery is not caused by platelet activation. Indeed, established markers of platelet activation, platelet-bound P-selectin expression, ${ }^{7}$ soluble P-selectin, ${ }^{9}$ and a possibly new indicator of platelet activation, platelet-bound $\mathrm{TF},{ }^{13}$ did not show sensible changes in the postoperative period up to 1 month.

In addition, the parallel in vivo behavior of basal and ADP-stimulated platelet expression of P-selectin, which not only mediates the adherence of platelets to leukocytes and endothelial cells but also enhances the expression of TF on monocytes ${ }^{14}$ and of platelet-bound TF further rules out a possible role of platelet activation in the postoperative period. This observation confirms and extends previous findings documenting similar behavior of these 2 differently located markers of platelet activation after ADP stimulus in vitro in healthy subjects. ${ }^{13}$

Particular attention should be given to TF, one of the main contributors of the early postsurgical hemostatic activation phase, a major determinant of atherosclerotic plaque thrombogenicity, ${ }^{15}$ and the most likely mechanism of early saphenous vein graft failure caused by graft thrombosis. ${ }^{16}$ Interestingly, cell-associated TF did not sensibly change in the perioperative period. Four days after the operation, however, TF circulating in plasma significantly increased, in accordance with previous findings from our group documenting a trend toward increased levels of this variable occurring a few days after CABG ${ }^{1,5}$ Circulating TF antigen is detectable in blood from healthy subjects, and increased levels of this protein are found in patients with cardiovascular disease, sepsis, and hematologic and coagulation disorders. ${ }^{17}$ It recognizes several different cellular sources (eg, disrupted atherosclerotic plaques, platelets, apoptotic leukocytes, and endothelial cells), can circulate freely in the blood or in the form of cell-derived microparticles, and might contribute to thrombus propagation, ${ }^{17-19}$ even though, depending on clinical situations, it might or might not bear procoagulant properties. ${ }^{19}$

The increase in soluble TF levels, which is common to CABG and OPCAB, might at least in part explain the increase in thrombin generation markers previously described from our group that occurs in the postoperative period of both $C A B G^{1,2,5}$ and $\mathrm{OPCAB}^{5}$ operations and that lasts up to 30 days after the operation. A possible explanation for the less protracted increase in TF with respect to thrombin generation markers is that TF activity of blood might need to be rapidly modulated and confined outside of the flowing blood or inside of the cells in contact with it to avoid excessive coagulation activation. In fact, it has been previously described that sensible amounts of TF might exist in an encrypted nonfunctional form on microparticles, ${ }^{20}$ which are a heterogeneous family of small membrane vesicles released from different cells (eg, endothelial cells, mono- 
cytes, granulocytes, and platelets) on activation or during apoptosis and act as transcellular effectors showing, on certain conditions, highly procoagulant features. ${ }^{21,22}$

Finally, no differences were detected between on-pump and off-pump operations in all the markers studied, with the exception of intraoperative higher levels of soluble P-selectin in patients in the CABG group, with the postoperative behavior of this marker being very similar in both groups. This adds further support to the hypothesis that, after an early phase of coagulation activation, where differences in some hemostatic variables do occur, CABG and OPCAB show a very similar pattern of biologic pathways activation not related to CPB and probably caused by the surgical trauma common to both procedures. ${ }^{5}$

In conclusion, cell-associated TF and P-selectin do not contribute to the postoperative procoagulant response that occurs in the first month after coronary bypass surgery performed both on pump and off pump, whereas the postoperative increase of plasma TF levels is the common mechanism that might in part explain the postoperative prothrombotic state occurring in low-risk patients undergoing uneventful CABG and OPCAB. It is possible, however, that different scenarios might occur in patients with important thrombotic or bleeding complications.

There is the need for future studies addressing the behavior of hemostatic variables in patients with thrombotic or hemorrhagic postoperative complications.

\section{References}

1. Parolari A, Colli S, Mussoni L, Eligini S, Naliato M, Wang X, et al. Coagulation and fibrinolytic markers in a two-month follow-up of coronary bypass surgery. J Thorac Cardiovasc Surg. 2003;125:336-43.

2. Mannucci L, Gerometta PS, Mussoni L, Antona C, Parolari A, Salvi L, et al. One month follow-up of haemostatic variables in patients undergoing aortocoronary bypass surgery. Effect of aprotinin. Thromb Haemost. 1995;73:356-61.

3. Moor E, Hamsten A, Blomback M, Herzfeld I, Wiman B, Ryden L. Hemostatic factors and inhibitors and coronary artery bypass grafting: preoperative alterations and relation to graft occlusion. Thromb Haemost. 1994;72:335-42.

4. Li N, Astudillo R, Ivert T, Hjemdahl P. Biphasic pro-thrombotic and inflammatory responses after coronary artery bypass surgery. J Thromb Haemost. 2003;1:470-6.

5. Parolari A, Mussoni L, Frigerio M, Naliato M, Alamanni F, Galanti A, et al. Increased prothrombotic state lasting as long as one month after on-pump and off-pump coronary surgery. J Thorac Cardiovasc Surg. 2005;130:303-8.

6. Ernoffson M, Thelin S, Siegbahn A. Monocyte tissue factor expression, cell activation, and thrombin formation during cardiopulmonary bypass: a clinical study. J Thorac Cardiovasc Surg. 1997;113:576-84.

7. Chung JH, Gikakis N, Rao AK, Drake TA, Colman RW, Edmunds LH. Pericardial blood activates the extrinsic coagulation pathway during clinical cardiopulmonary bypass. Circulation. 1996:93:2014-8.

8. Philippou H, Adami A, Davidson SJ, Pepper JR, Burman JF, Lane DA. Tissue factor is rapidly elevated in plasma collected from the pericardial cavity during cardiopulmonary bypass. Thromb Haemost. 2000; 84:124-8.

9. Weerasinghe A, Taylor KM. The platelet in cardiopulmonary bypass. Ann Thorac Surg. 1998;66:2145-52.

10. Eagle KA, Guyton RA, Davidoff R, Ewy GA, Fonger J, Gardner TJ, et al. ACC/AHA guidelines for coronary artery bypass graft surgery: executive summary and recommendations. A report of the American College of Cardiology/American Heart Association Task Force on Practice Guidelines (Committee to Revise the 1991 Guidelines for Coronary Artery Bypass Graft Surgery). Circulation. 1999;100:1464-80.

11. Casati V, Gerli C, Franco A, Della Valle P, Benussi S, Alfieri O, et al. Activation of coagulation and fibrinolysis during coronary surgery: onpump versus off-pump techniques. Anesthesiology. 2001;95:1103-9.

12. Biglioli P, Cannata A, Alamanni F, Naliato M, Porqueddu M, Zanobini $\mathrm{M}$, et al. Biological effects of off-pump vs. on-pump coronary artery surgery: focus on inflammation, hemostasis and oxidative stress. Eur J Cardiothorac Surg. 2003;24:260-9.

13. Camera M, Frigerio M, Toschi V, Brambilla M, Rossi F, Cottell D, et al. Platelet activation induces cell-surface immunoreactive tissue factor expression, which is modulated differently by antiplatelet drugs. Arterioscler Thromb Vasc Biol. 2003;23:1690-6.

14. Shebuski RJ, Kilgore KS. Role of inflammatory mediators in thrombogenesis. J Pharmacol Exp Ther. 2002;300:729-35.

15. Tremoli E, Camera M, Toschi V, Colli S. Tissue factor in atherosclerosis. Atherosclerosis. 1999;144:273-83.

16. Motwani JG, Topol EJ. Aortocoronary saphenous vein graft disease: pathogenesis, predisposition, and prevention. Circulation. 1998;97: 916-31.

17. Mackman N. Role of tissue factor in hemostasis, thrombosis, and vascular development. Arterioscler Thromb Vasc Biol. 2004;24: 1015-22.

18. Rauch U, Nemerson Y. Circulating tissue factor and thrombosis. Curr Opin Hematol. 2000;7:273-7.

19. Sturk-Maquelin KN, Nieuwland R, Romijn FP, Eijsman L, Hack CE, Sturk A. Pro- and non-coagulant forms of non-cell-bound tissue factor in vivo. J Thromb Haemost. 2003;1:1920-6.

20. Giesen PL, Nemerson Y. Tissue factor on the loose. Semin Thromb Hemost. 2000;26:379-84.

21. Diamant M, Tushuizen ME, Sturk A, Nieuwland R. Cellular microparticles: new players in the field of vascular disease? Eur J Clin Invest. 2004;34:392-401.

22. Morel O, Toti F, Hugel B, Freyssinet JM. Cellular microparticles: a disseminated storage pool of bioactive vascular effectors. Curr Opin Hematol. 2004;11:156-64. 


\section{Electronic Appendix Materials}

Adenosine diphosphate (ADP) and Escherichia coli lipopolysaccharide were from Sigma. Fluorescein isothiocyanate (FITC)labeled monoclonal antibody (mAb) anti-human $\mathrm{TF}$ was from American Diagnostica. FITC-conjugated anti-human P-selectin $\mathrm{mAb}$ and phycoerythrin (PE)-conjugated anti-human glycoprotein $\mathrm{IIb} / \mathrm{III} \mathrm{mAb}$ (CD41) were from Instrumentation Laboratories. PE-conjugated anti-human CD14 and FITC- and PE-labeled IgG1 isoantibodies were from Becton Dickinson.

\section{Platelet Analysis by Means of Flow Cytometry}

Platelet-associated TF and P-selectin expression were determined in whole blood (WB) by means of flow cytometry. Levels of the proteins were assessed both under resting conditions and on stimulation with ADP. Briefly, immediately after collection, $5 \mu \mathrm{L}$ of blood was stimulated for 15 minutes at room temperature with ADP (10 $\mu \mathrm{mol} / \mathrm{L}$, stimulated sample) or vehicle (control sample) without stirring. Then samples were incubated for 15 minutes with saturating concentrations of the specific FITC- or PE-conjugated antibodies and analyzed with a flow cytometer (FACSCalibur, Becton Dickinson) equipped with a 15-mW, air-cooled, 488-nm argon-ion laser. Leukocytes were excluded with a combination of size- and platelet-specific marker (CD41) gating. The FITC-positive events (TF and P-selectin) were determined in 10,000 CD41 ${ }^{+}$ platelets per sample. Isotype control mAbs were used in each experiment to determine nonspecific background $\mathrm{mAb}$ binding. Mean FITC fluorescence intensity was calculated from fluorescence histograms for the gated population, and data were analyzed with a computer (CELLQuest software, Becton Dickinson). The results are expressed as the percentage change from baseline (Figures 1 and 2) and as mean fluorescence intensity (MFI; Table E2).

\section{Monocyte Analysis by Means of Flow Cytometry}

For flow cytometric determination of monocyte TF expression, $500 \mu \mathrm{L}$ of unstimulated $\mathrm{WB}$ and $500 \mu \mathrm{L}$ of WB stimulated with lipopolysaccharide $(10 \mathrm{ng} / \mathrm{mL})$ were incubated for 5 hours at $37^{\circ} \mathrm{C}$ without stirring. Then samples were fixed with $1 \%$ formaldehyde for 30 minutes at $4^{\circ} \mathrm{C}$ and washed twice. The fixed samples were incubated for 30 minutes with saturating concentrations of PElabeled anti-CD14 and FITC-labeled anti-TF and then resuspended in $700 \mu \mathrm{L}$ of lysis buffer and analyzed by means of flow cytometry. The TF-positive events were determined in $3000 \mathrm{CD}^{+} 4^{+}$ monocytes per sample. Isotype control mAbs were used in each experiment to determine nonspecific background mAb binding. Mean FITC fluorescence intensity was calculated from florescence histograms for the gated population, and data were analyzed with a computer (CELLQuest software, Becton Dickinson). The results are expressed as percentage change from baseline (Figures 1 and 2) and as MFI (Table E2).

\section{Plasma TF and P-selectin}

Plasma TF and P-selectin levels were determined by means of enzyme-linked immunosorbent assay (ELISA; American Diagnostica and R\&D Systems, respectively), according to the manufacturer's instructions. 
TABLE E1. Clinical variables in the study population

\begin{tabular}{|c|c|c|c|}
\hline Variable & CABG (n = 15) & OРCAB (n = 15) & $P$ value \\
\hline Age (y) & $64 \pm 1.4$ & $65 \pm 1.2$ & .58 \\
\hline Male sex $(\%)$ & $10(67 \%)$ & $9(60 \%)$ & $>.99$ \\
\hline Previous MI (\%) & $9(60 \%)$ & $6(40 \%)$ & .47 \\
\hline Type I diabetes (\%) & $1(7 \%)$ & $2(13 \%)$ & $>.99$ \\
\hline Type II diabetes (\%) & $3(20 \%)$ & $3(20 \%)$ & $>.99$ \\
\hline COPD $(\%)$ & $2(13 \%)$ & $4(27 \%)$ & .65 \\
\hline Hypertension (\%) & $13(87 \%)$ & $10(67 \%)$ & .39 \\
\hline Echocardiographic EF (\%) & $56 \pm 1.5$ & $58 \pm 1.8$ & .39 \\
\hline Preoperative hematocrit (\%) & $39 \pm 0.9$ & $38 \pm 1.2$ & .53 \\
\hline Diseased coronary vessels & $2.9 \pm 0.16$ & $2.8 \pm 0.13$ & .63 \\
\hline Distal anastomoses & $3.2 \pm 9.29$ & $2.8 \pm 0.23$ & .27 \\
\hline CPB time (min) & $108 \pm 5.5$ & - & - \\
\hline Crossclamp time (min) & $83 \pm 3.7$ & - & - \\
\hline 2-h bleeding (mL) & $97 \pm 8.3$ & $86 \pm 6.4$ & .29 \\
\hline 24-h bleeding (mL) & $450 \pm 21$ & $467 \pm 23$ & .58 \\
\hline Total bleeding $(\mathrm{mL})$ & $601 \pm 15$ & $639 \pm 18$ & .11 \\
\hline Ventilation time (h) & $6.4 \pm 1.34$ & $5.4 \pm 1.61$ & .08 \\
\hline
\end{tabular}

$C A B G$, On-pump coronary artery bypass grafting; $O P C A B$, off-pump coronary artery bypass grafting; $M I$, myocardial infarction; COPD, chronic obstructive pulmonary disease; $E F$, ejection fraction; $C P B$, cardiopulmonary bypass.

TABLE E2. Tissue factor and P-selectin levels before, during, and after the operation in the CABG and OPCAB groups

\begin{tabular}{|c|c|c|c|c|c|c|}
\hline & & Baseline & Protamine & $4 \mathrm{~d}$ & $8 \mathrm{~d}$ & $30 \mathrm{~d}$ \\
\hline \multirow[t]{2}{*}{ Plasma tissue factor $(\mathrm{pg} / \mathrm{mL})$} & CABG & $157 \pm 5.5$ & $233 \pm 7.3$ & $275 \pm 12.9$ & $217 \pm 5.5$ & $157 \pm 5.6$ \\
\hline & OPCAB & $145 \pm 6.2$ & $169 \pm 3.9$ & $263 \pm 16.5$ & $145 \pm 5.5$ & $150 \pm 4.8$ \\
\hline \multirow{2}{*}{$\begin{array}{l}\text { Unstimulated monocyte tissue } \\
\text { factor expression (MFI) }\end{array}$} & CABG & $0.95 \pm 0.043$ & $1.00 \pm 0.040$ & $0.93 \pm 0.032$ & $1.01 \pm 0.043$ & $0.93 \pm 0.048$ \\
\hline & OPCAB & $0.95 \pm 0.037$ & $0.89 \pm 0.029$ & $0.93 \pm 0.039$ & $0.99 \pm 0.043$ & $0.87 \pm 0.021$ \\
\hline \multirow{2}{*}{$\begin{array}{l}\text { Stimulated monocyte tissue } \\
\text { factor expression (MFI) }\end{array}$} & CABG & $1.59 \pm 0.094$ & $1.76 \pm 0.136$ & $1.41 \pm 0.080$ & $1.54 \pm 0.115$ & $1.51 \pm 0.061$ \\
\hline & OPCAB & $1.46 \pm 0.115$ & $1.25 \pm 0.067$ & $1.43 \pm 0.107$ & $1.57 \pm 0.152$ & $1.38 \pm 0.048$ \\
\hline \multirow{2}{*}{$\begin{array}{l}\text { Platelet tissue factor expression } \\
\text { (MFI) }\end{array}$} & CABG & $2.15 \pm 0.208$ & $1.76 \pm 0.126$ & $2.40 \pm 0.246$ & $2.20 \pm 0.192$ & $1.92 \pm 0.147$ \\
\hline & ОРСАВ & $1.83 \pm 0.150$ & $1.67 \pm 0.110$ & $1.75 \pm 0.152$ & $1.78 \pm 0.139$ & $1.62 \pm 0.166$ \\
\hline \multirow{2}{*}{$\begin{array}{l}\text { ADP-induced platelet tissue } \\
\text { factor expression (MFI) }\end{array}$} & CABG & $3.37 \pm 0.182$ & $2.85 \pm 0.139$ & $3.53 \pm 0.251$ & $3.22 \pm 0.190$ & $2.68 \pm 0.083$ \\
\hline & OPCAB & $3.15 \pm 0.230$ & $2.82 \pm 0.203$ & $2.63 \pm 0.190$ & $2.68 \pm 0.142$ & $2.61 \pm 0.166$ \\
\hline \multirow{2}{*}{$\begin{array}{l}\text { Platelet P-selectin expression } \\
\text { (MFI) }\end{array}$} & CABG & $0.94 \pm 0.019$ & $0.90 \pm 0.027$ & $0.97 \pm 0.024$ & $0.89 \pm 0.024$ & $1.03 \pm 0.067$ \\
\hline & OPCAB & $0.90 \pm 0.035$ & $0.89 \pm 0.037$ & $0.86 \pm 0.013$ & $0.90 \pm 0.021$ & $0.98 \pm 0.032$ \\
\hline \multirow{2}{*}{$\begin{array}{l}\text { ADP-induced platelet P-selectin } \\
\text { expression (MFI) }\end{array}$} & CABG & $3.97 \pm 0.496$ & $3.04 \pm 0.283$ & $4.32 \pm 0.267$ & $4.01 \pm 0.323$ & $3.84 \pm 0.393$ \\
\hline & OРCAB & $2.67 \pm 0.416$ & $2.32 \pm 0.179$ & $2.44 \pm 0.182$ & $2.60 \pm 0.198$ & $3.16 \pm 0.390$ \\
\hline \multirow[t]{2}{*}{ Soluble P-selectin (ng/mL) } & CABG & $101 \pm 3.7$ & $131 \pm 3.4$ & $111 \pm 3.5$ & $133 \pm 3.1$ & $107 \pm 2.5$ \\
\hline & ОРСАВ & $93 \pm 3.0$ & $64 \pm 1.3$ & $97 \pm 2.4$ & $113 \pm 4.4$ & $93 \pm 2.1$ \\
\hline
\end{tabular}

$\overline{C A B G}$, On-pump coronary artery bypass grafting; $O P C A B$, off-pump coronary artery bypass grafting; $M F I$, mean fluorescence intensity; $A D P$, adenosine diphosphate. 